Грачиков Е.H.

DOI: 10.7256/2305-560X.2015.3.14641

\title{
ВНЕШНЯЯ ПОЛИТИКА КИТАЯ: СТРАТЕГИИ В КОНТЕКСТЕ ИДЕНТИЧНОСТИ И ГЛОБАЛЬНОЙ ПЕРСПЕКТИВЫ
}

\begin{abstract}
Аннотация. Цель статьи, ее главная сверхзадача, - осмысление основной особенности внешней политики современного Китая, заключающейся в дипломатических стратегиях, которые руководство страны вырабатывала, осуществляла и меняла в зависимости от политической ситуации как внутри страны, так и за рубежом. Автор стремился объединить в один рисунок несколько композиций, с разных сторон характеризующих внешние отношения Китая: краткую историю развития государственной идентичности - исключительно западный дискурс, слабо отраженный в китайских исследованиях, но важный для понимания как самого Китая, так и его внешней политики, и смену дипломатических стратегий - внешнеполитическую практику, связанную с китайской логикой и философской мыслью. Характеристики каждого периода внешней политики Китая даются такими, какими они видятся самим китайским авторам. Глобальный Китай рассматривается в философском и политическом контексте. Статью отличают тщательный библиографический анализ китайских источников, внимательное отношение к истории политической мысли Китая, компаративный подход к осмыслению взаимодействия Китая с окружающим его мировым пространством. Новизна исследования заключается в том, что в статье предпринята попытка концептуализации всей внешней политики КНР (1949-2015) в форматах ранее мало изученных: стратегии, идентичность и глобальность. Без учета этих составляющих зачастую сложно понять внешнеполитическую логику и поступки Китая на международной арене. Анализ генезиса идентичности, стратегий и положения Китая относительно международной системы (включенности/исключенности) помогает разобраться в сегодняшней и, возможно, завтрашней внешней политике Китая.
\end{abstract}

Ключевые слова: внешняя политика Китая, идентичность Китая, стратегия, дипломатические стратегии, "держаться одной стороны», партнерская дипломатия, "один фронт", ревизионистская держава, глобальная держава, глобальные ценности, внешняя политика Китая, идентичность Китая, стратегия, дипломатические стратегии, "держаться одной стороны», партнерская дипломатия, "один фронт», ревизионистская держава, глобальная держава, глобальные ценности, внешняя политика Китая, идентичность Китая, стратегия, дипломатические стратегии, "держаться одной стороны", партнерская дипломатия, "один фронт", ревизионистская держава, глобальная держава, глобальные ценности, внешняя политика Китая, идентичность Китая, стратегия, дипломатические стратегии, "держаться одной стороны», партнерская дипломатия, "один фронт», ревизионистская держава, глобальная держава, глобальные ценности.

Review: The aim of the article is to understand the main peculiarity of the foreign policy of modern China, the diplomatic strategies which have been changed by its leadership depending on the political situation in the country or abroad. The author attempts to combine several aspects characterizing Chinese foreign policy: the brief history of the state identity developmenta solely Western discourse which is poorly reflected in Chinese studies but important for understanding of China itself and its foreign policy; and the change of diplomatic strategies - a foreign policy practice connected with Chinese logic and philosophy. The author adduces the characteristics of each period of Chinese foreign policy typical for the Chinese authors. The article contains a thorough analysis of Chinese resources; it is characterized by a careful bibliographic analysis, attention to the history of the Chinese political thought, the comparative approach to the understanding of interrelations between China and the rest of the world. The novelty of the research lies in the fact that the author attempts to conceptualize Chinese foreign policy (1949-2015) from the perspectives which haven't yet been studied thoroughly enough: strategies, identity, globality. Without paying attention to these components it is hard to understand the logic of Chinese foreign policy and actions on the international scene. The analysis of genesis of identity, strategies and position of China in relation to the international system (inclusiveness/exclusiveness) will help to understand the current and, probably, the future foreign policy of China.

Keywords: foreign policy of China, global values, global power, revisionist power, "a battle line", partnership diplomacy, "leaning to one side", diplomatic strategies, strategy, identity of China, foreign policy of China, global values, global power, revisionist power, "a battle line", partnership diplomacy, "leaning to one side", diplomatic strategies, strategy, identity of China, foreign policy of China, global values, global power, revisionist power, "a battle line", partnership diplomacy, "leaning to one side", diplomatic strategies, strategy, identity of China, foreign policy of China, identity of China, strategy, diplomatic strategies, "leaning to one side", partnership diplomacy, "a battle line", revisionist power, global power, global values. 
$\mathrm{B}$ нешняя политика Китая, как великой державы и цивилизации, не может рассматриваться и концептуализироваться в каком-нибудь одном формате (истории дипломатии или политики), тем более, в западном дискурсе. Она требует более широкой палитры китайских источников, китайских взглядов и китайского философского осмысления, поскольку вплоть до сегодняшнего дня Запад, по образному выражению философа Чжао Тиняна, так и не понял китайский дух, который имеет «конфуцианское сердце», определяющее базовые ценности, и «даосский ум», вырабатывающий стратегии [1].

Внешняя политика Китая имеет отличительную «родовую» особенность - её формулирование в виде дипломатических стратегий, которые подчиняются определенной общей долгосрочной стратегии и геостратегии. В течение всей многотысячелетней истории китайские князья, императоры и руководители вплоть до начала 21 века использовали одну геостратегию - сухопутную, которая предусматривала развитие «власти Суши»: в экономике - это сельское хозяйство, в национальной обороне - сухопутные силы, в сношениях с внешним миром - приграничные страны. Это было внутриравнинное, замкнутое и самодостаточное развитие, то что принято называть «сельскохозяйственной цивилизацией». Даже морское вторжение западных стран («опиумные» войны Англии), модернизация Китая, социалистическое строительство не изменили общий характер этой геостратегии.

Только вступление в ВТО и резкое расширение внешнеэкономических связей (КНР - главный торговый партнер для 120 стран), зависимость от внешних ресурсов (КНР завозит из-за рубежа $40 \%$ необходимого сырья и вывозит на внешние рынки более $60 \%$ всей произведенной в стране продукции) поставили морские вопросы в повестку дня китайской дипломатии. В 21 веке Китай занят решением проблемы обеспечения безопасности источников производственного сырья, рынков сбыта своих товаров и транспортных путей их доставки. Китай сменил вектор своего развития и приступил к реализации морской геостратегии.

Вторая особенность внешней политики Китая состоит в том, что она больше связана с китайской логикой, философией и мировозрением, чем с определенной идеологией (марксизм, либерализм). Современный китайский философ так интерпретирует подобный феномен. «Ицзин» («Книга перемен») и даосизм объясняют общую китайскую методоло- гию рационального мышления и поступков, включая гибкий путь изменений вместе с изменениями, осторожный подход, если дело идет о вызовах и рисках, и активных стратегиях для различных ситуаций и обстоятельств, а также естественный подход для понимания и принятия будущего непредсказуемых возможностей. Это хорошо описано у Лаоцзы в метафоре о воде, поэтому я называю ее методологией воды, с помощью которой китайские умы рассматривают ситуацию, условия и возможности для того, чтобы сделать свой выбор более гибким, таким как вода, которая находит самый короткий путь к необходимому месту» [4: 136].

\section{Идентичность Китая в мировом пространстве}

Развитие китайской государственности прошло условно говоря три больших этапа (сейчас идет четвертый), в каждом из которых Китай представал для остального мира с вполне сформировавшимся типом идентичности. Вехами в этом историческом процессе генезиса государства, от империи до республики, и идентичности, от индивидуальной до коллективной, являются: образование централизованного государства - Империи Цинь, первая «опиумная» война, политика реформ и открытости Дэн Сяопина, мировой финансовый кризис.

Первый, 2212. до н.э. - 1840г., ролевая идентичность империи.

Характерные особенности - создание в Восточной Азии «международного порядка, основанного на однополярной системе» [7: 1], которая скреплялась родоплеменными, династийными и данническими отношениями; доминирование Китая над другими этносами и странами в экономической, культурной и военной сферах; замкнутость китайской мировой системы, обусловленная географическим рельефом, китаецентризмом и самодостаточностью; общность конфуцианских морально-этических норм; преобладание геостратегии с опорой на силу Суши.

Второй, 1840г. - 1978г., ролевая идентичность полуколонии, зависимой или играющей второстепенные роли страны.

Главные особенности - упадок государственной системы; военная неспособность отстаивать суверенитет страны; изолированность, провал всех попыток играть самостоятельную роль в существующей системе международных отношений; отсутствие геостратегии. Две древние геостратегии Китая были ошибочны и привели великую империю к упадку. Речь идет о «китаецентризме» 
(zhongguo zhongxinlun) и «преувеличении роли Суши и недооценке роли Моря» (zhonglu qinhai) [8: 85-88]. Одной из главных причин «конца» империи и последовавшей политической раздробленности была отсталая «система» Китая, т.е. её общественно-политический строй [9: 003]. Большую часть своей истории Китай находился вне системы международных отношений (до восстановления своих прав в ООН в 1971 г.), был наблюдателем международных отношений.

Третий, 1979г. - 2008г., переходный период, возрождение идентичности великой державы.

Впервые в истории Китая идет формирование коллективной идентичности, включенности во все институты мировой системы. Характерные черты противоречие между ростом экономической мощи и невозможностью её превращения на данном этапе в военно-политическое влияние на мировые события; технологическое отставание (сохраняется положение догоняющего); попытка формирования собственного геополитического (ШОС, БРИКС, ACЕАН+1) и геоэкономического (зоны свободной торговли КНР с более чем 20 странами) пространства; быстрая смена стратегий: от «приглашения к себе» до «выхода за рубеж» [10: 1-17]; резкое расширение сферы национальных интересов от «приграничных районов» (14 стран) Восточной Азии до «больших приграничных районов» (29 стран); продолжение сухопутной геостратегии.

Четвертый, 2009г. - наст. время, идентичность глобальной державы.

Характеризуется саморефлексией исключительно в глобальном контексте с собственной системой глобальных ценностей. Упор на морскую геостратегию «на Юг, через Моря, в глобальный Мир» [12]. В декабре 2008 г. впервые за 600 последних лет отряд военных кораблей ВМФ КНР покидает прибрежные воды Китая и направляется на антипиратское патрулирование к берегам Сомали. 23 сентября 2012 г. первый китайский авианосец (бывший «Варяг») передан военно-морским силам страны. Китай становится океанической державой, способной эффективно контролировать морские транспортные пути.

\section{Внешняя политика как естественный процесс смены стратегий}

Весь большой исторический этап республиканского Китая (Китайская Республика: 1912-1949; КНР: 1949-наст.вр.) профессор и декан факультета международной политики Университета междуна- родных отношений («кузница» дипломатических кадров КНР) Линь Хунюй делит на четыре периода. Подготовительный период: 1919-1949. Парижскую конференцию 1919 года и созданную «Версальско-Вашингтонскую» систему он рассматривает как начало глобального управления, когда Китай сделал первые шаги по взаимодействию с другими странами. Этот период делится на две фазы: 19191942, Китай «под управлением», и, 1943-1949, «пассивного вовлечения» - приобретение равных международных прав путем участия в ряде глобальных конференций (Каирской, Думбартон-Оксе), но только в качестве «стратегической пешки» США. Трудный период: 1949-1971, характеризуется двумя трендами: «холодной» войной во внешней обстановке и «левизной»- во внутренней политике. Характер международных отношений определяли две страны: США и СССР. Китай в это время активно поддерживает революционные движения в других странах («экспорт революций»), что приводит к ее изоляции на международной арене. Формальный период: 1971-2001. Восстановление прав в ООН позволило КНР на официальном уровне включиться в работу многих международных структур, постепенно становясь полноправным членом международного сообщества. Современный период: 2001 - наст. время. Вступление Китая 11 декабря 2001 г. в ВТО стало исторической вехой и означало завершение интеграции страны в мировую международную систему. Финансовый кризис 2008 г. запустил процесс перераспределения власти между главными игроками международных отношений, что сопровождалось её децентрализацией от национальных государств к гражданским обществам и от сегодняшних великих держав к нарождающимся. С 2008 г. Китай работает над реформированием существующего механизма глобального управления [13: 59-62].

Вышедший в начале 2013 г. первый в Китае «Прикладной справочник по международным отношениям» (под ред. Хуан Жиханя и Яо Юйфэя) представил историювнешней политики КНРв виде пятипериодов.Первый,1949-середина50-хгодов,дипломатия «трех великих решений»: «склониться в одну сторону», «начать все сначала», «навести порядок в доме, а потом приглашать гостей». Это расшифровывалось следующим образом: «установить союз с СССР», «не признавать дипломатические отношения, установленные правительством Чан Кайши, а начать все с начала», «на территории Китая ликвидировать все проявления империалистического влияния (за- 
крыть иностранные военные базы, банки, сеттльменты, школы, издательства, больницы и т.п.)». Второй период, середина 50-х г. - конец 60-х г., отказ от дипломатической политики «склониться в одну сторону», опора на более широкий круг стран Азии, Африки и Латинской Америки, борьба против ревизионизма и империализма (против СССР и США). Третий период, конец 60-х г. - конец 70-х г. Внешняя политика, также как и другие сферы деятельности государства, была подвержена влиянию «левых» идей. В 1971 г. восстанавливаются права КНР в ООН. В 1972 г. начинается процесс улучшения китайско-американских отношений. Китай принимает «дипломатическую политику» «одного фронта», «одной линии». К 1979 г. Китай поддерживал дипломатические отношения с 120 странами. Четвертый период, начало 80-х г. - конец 20-го столетия, характеризуется независимой и самостоятельной позицией. Подчеркивается, что Китай больше не будет вступать в стратегические отношения или полагаться на какую-либо великую державу. Для решения проблемы Сянгана (Гонконга) и Аомэня (Макао) предлагается формат «одна страна - две системы», который успешно осуществляется вместе с Англией и Португалией. Пятый период, начало 21 века - настоящее время, проводится политика поддержания существующей международной системы, основанной на принципах мирного сосуществования. Выдвинута идея гармоничного мира, направленная на совместное развитие [14: 151-153].

Периодизация внешней политики Китайской Народной Республики большинством китайских ученых, как правило, делится на два больших этапа, связанных с историей развития страны: 1949 г. - 1978 г. и 1978 г. - настоящее время, т.е. до и после 3 пленума ЦК КПК (18-22 декабря 1978 г.), в лице Дэн Сяопина объявившего о начале политики реформ в Китае [7: 28].

\section{I. Стратегия заключения союзов: 1949-1979.}

История внешней политики КНР первых тридцати лет ее существования во внутрикитайском дискурсе ни у кого не вызывает разночтений. Она содержится в одобренных ЦК КПК учебных материалах, статьях видных партийных деятелей и принята всем научным сообществом Китая. Незначительные расхождения (в 2-3 года) наблюдаются в конкретных датах начала и окончания того или иного этапа. Названия первых трех этапов у всех источников одинаковое. Е Цзычэн весь этот тридцатилетний период объединяет названием «стратегия заключения союзов», а последующие тридцать лет «стратегия не вступления в союзы» [15: 23]. Некоторые авторы первые тридцать лет характеризуют, как «период настоящей пустоты» или «период молчания» [16: 77], имея в виду, что средства массовой информации, общественные организации и простые граждане были ограничены в доступе к внешнеполитической информации и не могли открыто высказываться по поводу тех или иных шагов своего правительства на международной арене. Другие ученые отмечают, что до 1971 года Китай был не участником, а наблюдателем международных отношений и находился вне международной системы [17: 100]. Китай был исключен из мировой капиталистической системы и социалистического лагеря. Таким образом, с одной стороны, Китай был самым независимым актором в глобальной блоковой политике и, в тоже время, занимал изолированное положение [18: 117].

Многие ученые отмечают, что первые тридцать лет внешняя политика Китая строилась по принципу деления стран на врагов и друзей [23: 96]. Весь тридцатилетний период - это идентичность социалистической страны.

Первый период: 1949 г. - конец 50-х г.

Китай проводит дипломатическую стратегию «держаться одной стороны» - «и бянь дао». Это была политика развития всесторонних политических, экономических и идеологических отношений с Советским Союзом. Е Цзычэн дает более точные сроки (1949-1957) и поясняет, что это был «союз с СССР против США» [15]. Фу Мэнцзы уточняет, что «антагонизм Запада заставил Китай занять сторону Советского Союза и Восточной Европы и установить экономические связи с социалистическим рынком, но даже в таких условиях Китай оказывал влияние на мировую мысль» [19: 5].

Решение о союзе с Советским Союзом было принято в марте 1949 г. на втором пленуме ЦК КПК [20: 71]. Мао Цзэдун первый раз отметил необходимость «держаться одной стороны» в статье «0 демократической диктатуре народа» 30 июня 1949 г., всего за три месяца до провозглашения КНР.

Под лозунгом борьбы с «американским империализмом» Китай принимает активное участие в корейской войне 1950 - 1953 гг.

После завершения войны на корейском полуострове для создания благоприятного международного имиджа и выхода из международной изоляции Китай выступает с пятью принципами мирного сосуществования, которые включали: взаимное уважение территориальной целостности 
и суверенитета; ненападение; невмешательство во внутренние дела друг друга; равенство и взаимную выгоду; мирное сосуществование.

В области внутренней политикой, непосредственно связанной с внешней, ставилась задача завершения процесса освобождения страны от иностранного колониального влияния, т.е. возвращение под юрисдикцию Китая всей ее территории и всех органов власти: ликвидация западных сеттльментов и права их экстерриториальности, установление контроля над всеми таможенными органами, закрытие иностранных банков, военных баз, возвращение под полное управление правительства всей системы образования, здравоохранения и средств массовой информации, где продолжали действовать иностранные учреждения. Второй период: конец 50-х годов - конец 60-х г.

Осуществление стратегии борьбы «против империализма и против ревизионизма», т.е. против США и Советского Союза. Е Цзычэн добавляет, что это был период борьбы «на два фронта» и длился с 1958 по 1968 год [15].

Отличительной чертой внешней политики КНР этого времени является постепенный идеологический раскол во взаимоотношениях между КПК и КПСС, сворачивание экономического сотрудничества между СССР и КНР, постепенный рост «левых» тенденций во внешней политике, выразившийся в поддержке прокитайских группировок в компартиях стран третьего мира (т.н. «экспорт революций»).

К концу 60-х годов Китай смог установить дипломатические отношения не более чем с 20 странами. Кроме Франции, с которой КНР обменялся посольствами в 1964 г., все остальные представляли Азию и Африку.

Третий период: 1971 г. - 1978 г. (у Е Цзычэна этот период датируется 1969-1976 гг.).

Политика этого периода получила название «стратегия одной стороны» или «одной фронта». Она заключалась в стремлении формирофания самых тесных отношений с США. В геополитическом плане это была стратегическая линия, которая тянется от США и проходит через Японию, Китай, Пакистан, Иран, Турцию и заканчивается Европой - страны, объединенные Мао Цзэдуном по принципу расположения вдоль границ с Coветским Союзом, «по другую сторону» от СССР (отсюда название «одной стороны» и «одной линии»). Решением рабочего совещания ЦК КПК (ноябрь-декабрь 1978 г.) было одобрено установ- ление дипломатических отношений с США [20] и принята «дэнсяопиновская» «политика реформ и открытости», которая дала мощный толчок в развитии Китая.

После событий на острове Даманский на советско-китайской границе (1969 г.) Мао Цзэдун воспринимает военную опасность со стороны Советского Союза как вполне реальную и наиболее вероятную. Сказывается традиционное восприятие севера Суши (Советский Союз) как угрозы, которые в Китае по-прежнему, как и в древние времена, рассматриваются в качестве главных. Мао Цзэдун полностью переосмысливает геополитику Китая и начинает сближение с «дальним» союзником - США, чтобы противостоять «ближнему» противнику - СССР. Он пересматривает идеологические методы решения международных проблем, в результате чего Китаю удается нормализовать отношения с США и восстановить свое членство (вместо Тайваня - Республики Китай) в ООН (26 сессия Генеральной ассамблеи ООН, октябрь 1971).

В Совете безопасности ООН Китай с 1971 г. по 1979 г. проводит свою традиционную политику антигегемонизма и самоопределения наций. КНР поддерживает Движение неприсоединения, выступает с требованием политических изменений в Южной Родезии (Зимбабве) и Южной Африке. Критика Запада за поддержку этих двух расистских и незаконных режимов была достаточно острой, но даже по этим вопросам позиция КНР совпадала с позицией США на 29.2 \% (7 голосований «за» из 24). В целом же подходы Китая и США были одинаковыми 91 раз из 195 (по результатам голосования) или $46 \%$ [22: Loc. 558 of 7938].

Подводя итог первым тридцати годам внешней политики КНР, китайские исследователи обычно отмечают, что это был период преобладания взглядов деления мира на врагов и друзей, который привел к «определенному ограничению» внешних связей Китая. В 50-х годах основным объектом внешней политики Китая были социалистические страны, а в 60-х - развивающиеся страны. В 70-е года третий мир по-прежнему занимал главное место в политике Китая, хотя именно в эти годы «завершился процесс установления дипломатических отношений с основными западными странами» [23: 96]. В этот период 57 стран разорвали официальные связи с Тайванем и установили дипломатические отношения с КНР. В целом в 70-е годы Китай установил дипломатические отношения почти с 70 странами [24: 7]. 
II. Стратегия не вступления в союзы: 1979-2009.

На практике означала постепенное накапливание сил (экономической и военной мощи) без конфронтации с другими странами. Идентичность социалистической развивающейся страны [6:76]. Тридцать лет (1979г. - 2009г.) внешняя политика Китая характеризуется как многовекторная дипломатическая стратегия «стремиться ничем не проявлять себя (замкнуться в себе и ничем не выделяться)» "taoguang yanghui".

Четвертый период: 1978 г. - 1988 г.

В 1978 г. исполнилось всего два года после официального завершения «культурной революции». У руля партии в это время стояла временная политическая фигура в лице Хуа Гофэна. Борьба в Компартии Китая вылилась в «великое движение по раскрепощению сознания», которое получило название «практика - единственный критерий истины». После беспрецедентного рабочего совещания ЦК КПК, длившегося 36 дней, появился доклад Дэн Сяопина «Раскрепостить сознание, исходить из практики, сплачиваться воедино, чтобы смотреть вперед», в котором был окончательно утвержден поворот Китая к прагматичной внутренней и внешней политике.

По оценке китайских экспертов, международная ситуация в тот период была очень напряженной и в геополитическом плане не благоприятной для Китая. В декабре 1979 года Советский Союз ввел войска в Афганистан (100 тыс. чел.), что рассматривалось китайским руководством, как прямая военная угроза северо-западным границам Китая. В Монголии продолжал располагаться ограниченный контингент советских войск (100 тыс. чел.). Во Вьетнаме СССР активно использовал военно-морскую базу Камрань. Руководство Китая оценивало геополитическую ситуацию вокруг своей страны как стратегическое окружение Китая Советским Союзом.

Новая дипломатия «мира и развития», выдвинутая Дэн Сяопином, была направлена на установление добрососедских отношений со всеми странами и регионами мира. Основным лозунгом этой политики стали слова Дэн Сяопина «оставим в стороне разногласия, будем совместно развиваться».

В сентябре 1982 г. на 12 съезде КПК был впервые введен новый для дипломатии Китая термин «национальные интересы», который заменил «интересы пролетариата». Это был полный отказ от идеологических установок в области внешней политики и сигнал западному сообществу, что Китай готов стать частью международного сообщества на общепринятых и понятных для всех основаниях. К 1980 г. международное положение Китая значительно упрочилось, он поддерживал дипломатические отношения со 100 странами мира.

С 1981 г. по 1989 г. продолжается сближение позиций КНР и США по многим международным проблемам. «Одинаковость» при голосовании в Совете безопасности ООН возрастает с $46 \%$ до $73 \%$ (153 из 209 голосований). Китай полностью отказался от использования трибуны ООН для полемики и осуждения сверхдержав. Приоритетом становится установление тесных отношений с великими державами, структурами ООН и такими международными институтами как Международный валютный фонд и Всемирная торговая организация [22]. В сентябре 1988 года Дэн Сяопин впервые ставит задачу о создании нового международного порядка [23: 3].

Пятый период: 1989 г. - 1994 г.

Международная изоляция Китая, вызванная жестким подавлением студенческих выступлений на площади Тяньаньмэнь 4 июня 1989 года. В китайской историографии выступления молодежи в этот день обозначаются как «события 4 июня». Западные страны наложили эмбарго на поставки Китаю вооружений, военных технологий и оборудования двойного назначения, которое длится до сегодняшнего дня. Затормозился процесс интеграции Китая в международные организации. Россия не присоединилась к санкциям Запада и продолжала поставлять в Китай современную военную технику и вооружения, что делает и по сей день.

На 14 съезде КПК (12-18 октября 1992) из устава КПК исчез термин «пролетарский интернационализм», как основа внешней политики страны [16: 77]. В 1993 года для выхода из изоляции принимается стратегия «привлечь к себе» (qin jin lai), а внешняя политика этого периода в дальнейшем в научных работах получает название «рефлексивной дипломатии».

Лейтмотивом всей публичной китайской дипломатии уходящего века мог бы стать эпиграф к первой главе книги Си Лайвана «Дипломатические стратагемы»: «Китай во внешне политике никогда не был привязан к США. Во внешней политике двум мировым сверхдержавам Китай всегда говорил «нет» [25: 1]. Вместе с тем, голосование в Совете безопасности ООН, т.е. реальная практика китайской геополитики, показывает, что позиции Китая и США перестали отличаться друг от друга. Совпадение позиций возросло с 73 \% (в 80-е годы) 


\section{Международные отношения / International Relations / № 3 / 2015}

до $92.1 \%$ (591 из 642 голосований) в период с 1990 по 1999 год [22].

К 1998 г. Китай поддерживал отношения с 162 странами, стал членом около 400 международных организаций и участником более 100 международных договоров [24: 8]. Китай инкорпорировался во все международные структуры, завершился процесс социализации в международное сообщество.

Шестой этап: 1996 г. - 2008 г.

Выходом из международной изоляции стала дипломатия «партнерских отношений» (термин Жуань Цзунцзе). Этот период начинается в 1996 с подписания Китаем и Россией договора об установлении «партнерских отношений стратегического сотрудничества. В 1997 г. аналогичный договор о «конструктивных стратегических партнерских отношений» был заключен с США. В 2003 г. с Европейским Союзом достигнут договор об отношениях «всестороннего стратегического партнерства». В 2006 г. дошла очередь и до Германии в виде «партнерских отношений глобальной ответственности». Последнее подобное соглашение было подписано 6 января 2015 г. в Пекине между председателем КНР Си Цзиньпином и президентом КостаРики Луис Гильермо Солисом, которые объявили об установлении отношений стратегического партнерства, основанных на равенстве, взаимном доверии, сотрудничестве и обоюдном выигрыше.

Период с середины 90-х до середины «нулевых» годов 21 в. характеризуется, как политика сдержанного, «мягкого» отношения Китая к США, в результате которой на глобальном, региональном и двухстороннем уровне КНР избегала конфронтации с США.

На рубеже веков после вступления КНР в ВТО ускорена реализация стратегии «выхода за рубеж». Внешняя политика этого периода была названа «активной дипломатией» (иногда «энергетической дипломатией»). Место Китая в международной системе стало «перемещаться из периферийного пояса в ее центр» [23: 98].

За весь период с 2000 г. по 2009 г. в Совете безопасности ООН было проведено 636 голосований. Китай 622 раза (97.8 \%) проголосовал за предложенные резолюции. Этот показатель составил: для США - 619 (97.3), России - 622 (97.8), Франции 632 (99.4), Англии - 628 (98.7). Воспользовались правом «вето»: Китай - 2 раза $(0.3 \%)$, США - 9 (1.9), Россия - 4 (0.63), Франция - 0, Англия - 0. «Схожесть» голосования США и КНР продолжала расти с $92.1 \%$ (в 90-х годах) до 95.3 \% в 2000-х годах. Это, тем не менее, меньше чем процент одинакового голосования России и Китая - 98.4 \% [22]. Можно констатировать, что к концу первого десятилетия 21 века позиции пяти постоянных членов Совета безопасности мало чем отличались друг от друга. Фактически они в подавляющем большинстве случаев демонстрировали консолидированную позицию великих держав по проблемам глобальной безопасности. В этих обстоятельствах говорить о том, что позиции России и КНР были ближе, чем позиции США и КНР, по-моему, не приходится. Голосование по Сирии, когда Россия и Китай совместно применили право «вето», проголосовав против, говорит об очень редком, хотя безусловно приятном для нас, случае. Здесь обязательно необходимо уточнить, что голосование в Совбезе ООН касается вопросов глобальной безопасности и не может полностью характеризовать внешнюю политику Китая. Позиция КНР действительно совпадает с позицией России по многим актуальным мировым проблемам и кардинально расходится с подходами США к этим же проблемам.

В январе 2007 года Китай провел успешное испытание противоспутниковой ракеты, запущенной с земли, которое в мире однозначно рассматривалось как направленное против создававшейся ПРО США. В этом же месяце КНР впервые за последние десять лет (и пятый раз за все время членства в ООН) накладывает вето на инициированную США резолюцию ООН по поводу нарушения прав человека в Бирме. Многие наблюдатели восприняли это как окончание целой эпохи однополярной системы международных отношений [26: 42].

Мировой финансовый кризис показал Китаю, что США и руководимые им международные структуры (ВТО, МВФ, ВБ) не справляются с глобальными кризисами и, главное, больше не соответствуют мировому порядку [27: 23]. Понимая причины образования НАТО и систему военных союзов США в Восточной Азии, Китай впервые делает вывод, что «никогда не согласится принять их как часть международного порядка» [28: 3].

III. Стратегия глобальной державы с глобальными ценностями: 2009 г. - наст. время

Идентичность (экономической) сверхдержавы. Ли Кайшэн характеризует идентичность Китая в настоящее время (после «холодной» войны) как «развивающейся, социалистической, великой державы восточной культуры» [6: 76].

Приход к власти Си Цзиньпина знаменует новую внешнюю политику. Китай выдвигает гло- 
Мировая политика / World Politics

\section{Внешняя политика и концепции Китая и России}

\begin{tabular}{|c|c|c|c|c|c|c|c|}
\hline \multicolumn{2}{|c|}{ Концепции } & $\begin{array}{c}\text { 50-е годы } \\
20 \text { века }\end{array}$ & $\begin{array}{c}\text { 60-е годы } \\
20 \text { века }\end{array}$ & $\begin{array}{l}70-\text {-е годы } \\
20 \text { века }\end{array}$ & $\begin{array}{c}80-е \text { годы } \\
20 \text { века }\end{array}$ & $\begin{array}{c}90-е \text { годы } \\
20 \text { века }\end{array}$ & 21 век \\
\hline \multirow{2}{*}{$\begin{array}{l}\mathrm{K} \\
\mathrm{H} \\
\mathrm{P}\end{array}$} & Внешняя политика & \begin{tabular}{|c|} 
«СКлониться \\
в одну сторону» \\
\end{tabular} & \begin{tabular}{|c|} 
Борьба \\
против «двух» \\
\end{tabular} & $\begin{array}{l}\text { «Один } \\
\text { фронт» }\end{array}$ & $\begin{array}{c}\text { Независ-ть, самост-ть } \\
\text { и мирная политика }\end{array}$ & $\begin{array}{c}\text { Партнерская } \\
\text { дипломатия } \\
\end{array}$ & $\begin{array}{l}\text { Гармонич- } \\
\text { ный мир }\end{array}$ \\
\hline & $\begin{array}{l}\text { Внешнеполитические } \\
\text { концепции }\end{array}$ & \multicolumn{3}{|c|}{ Разделение на врагов и друзей } & Ни враг, ни друг & $\begin{array}{l}\text { Смело приоб- } \\
\text { ретать друзей }\end{array}$ & $\begin{array}{c}\text { Изменение } \\
\text { враждебных на } \\
\text { дружеств-ные }\end{array}$ \\
\hline \multirow[t]{2}{*}{$P Ф$} & Внешняя политика & $\begin{array}{c}\text { Противостояние } \\
\text { лагерей }\end{array}$ & Разрядка & $\begin{array}{l}\text { Борьба за } \\
\text { гегемонию }\end{array}$ & $\begin{array}{l}\text { Новое мышление } \\
\text { Горбачева }\end{array}$ & $\begin{array}{l}\text { Партнерская } \\
\text { дипломатия }\end{array}$ & $\begin{array}{l}\text { Дипломатия } \\
\text { независим-ти } \\
\text { и и самост-ти }\end{array}$ \\
\hline & $\begin{array}{l}\text { Внешнеполитические } \\
\text { концепции }\end{array}$ & \multicolumn{3}{|c|}{ Разделение на врагов и друзей } & $\begin{array}{l}\text { Непобедимый, } \\
\text { все друзья }\end{array}$ & $\begin{array}{c}\text { Смело } \\
\text { приобретать } \\
\text { друзей } \\
\end{array}$ & $\begin{array}{c}\text { Возможно } \\
\text { враг, возможно } \\
\text { друг } \\
\end{array}$ \\
\hline \multicolumn{2}{|c|}{$\begin{array}{c}\text { Китайско-российские } \\
\text { отношения }\end{array}$} & Сою3 & Полемика & $\begin{array}{l}\text { Противо- } \\
\text { действие }\end{array}$ & $\begin{array}{c}\text { На пути } \\
\text { к нормализации } \\
\text { отношений }\end{array}$ & $\begin{array}{c}\text { Дружествен- } \\
\text { ная держава/ } \\
\text { принципиаль. } \\
\text { партнер }\end{array}$ & $\begin{array}{c}\text { Отношения } \\
\text { стратегич-го } \\
\text { сотруднич-ва } \\
\text { и партнер-ва }\end{array}$ \\
\hline
\end{tabular}

Источник: Di 12 zhang. Zhong e guanxi (Gao Fei zhu), zai Daguo guanxi yu Zhongguo waijiao / Qin Yaqing zhubian. Beijing: Shijie zhishi chubanshe, 2011nian, di 40 уе (Глава 12. Китайско-российские отношения (подготовлена Гао Фэем) / «Отношения великих держав и дипломатия Китая». Глав. ред. Цинь Яцин. Пекин: Изд. Шицзе чжиши. 2011, с. 407).

бальные инициативы по формированию нового международного порядка, основанного на китайских традиционных ценностях, которые предлагаются в качестве глобальных. К этим предложениям можно отнести: «гармоничный мир», «новая модель взаимоотношения великих держав», «китайская мечта», «общество с общей судьбой» и «перспектива добродетельности и выгоды».

Стратегический характер внешней политики Китая хорошо представлен (в контексте КНР СССР/Россия) в нижеследующей таблице.

\section{Китай в политическом воображении мира: проблема восприятия}

Превращение Китая в глобальную державу стало заметным явлением в мировой политике. Китай стал частью глобальной экономики, глобальной науки и глобальной политики. Ученые многих стран исследуют проблемы взаимосвязи и взаимовлияния между Китаем и другими великими державами, Китаем и международными организациями. Каждый исследователь придерживается своей теоретической традиции и описывает свою точку зрения на перспективы отношений Китая с международной системой. Существуют эпистемологические и цивилизационные различия в подходах ученых Азии, Европы и Америки к китайской проблематике, которые можно объединить в три группы.

Первая - воспринимает международную систему, как во многом детерминированную собственной структурой. С этой точки зрения, международная структура определяет интересы и действия стран-членов этой системы. Теории «структурного реализма» часто затрагивают и формируют дискурс о влиянии Китая на международную систему, где главное внимание уделяется стабильности системы (т.е. стабильности баланса сил и интересов). Рост комплексной мощи Китая и ее требование достойного места в международных структурах нарушают эту стабильность. Китай, в связи с этим, называют «ревизионистской», т.к. он предлагает ревизовать, пересмотреть сложившийся баланс сил и интересов [29: 1-12].

Вторая группа выражает взгляды тех, кто выделяет саму систему в центр исследований и рассматривает международную систему, как «международное общество». Государства-нации выступают в этом обществе в качестве ее членов, которые разделяют общие ценности, нормы и порядки. Стандарты международного сообщества выступают как общие ценности. Западные ученые не раз поднимали вопрос о том, что неевропейские страны, в первую очередь Китай, должны соблюдать стандарты поведения и действия. Высказываются опасения, что, учитывая богатую и древнюю культуру и политические традиции, Китаю будет сложно воспринять чужие европейские ценности как свои собственные. Проблема ценностей уже сейчас становится главным камнем преткновения на пути сближения Китая и Европы [30]. С 2006 г. начинает меняться в худшую сторону имидж Китая в Европе, а с 2008 г. образ Европы в глазах китайцев. Главной причиной становится отсутствие общих ценностей, столкновение различных идентичностей. Европа смотрит на Китай через 
призму трех шаблонов: ориентализм/таинственность, коммунизм/авторитаризм, конкуренция/ страх. Китайский взгляд на Европу окрашен тремя эмоциями: недовольство за беды, которые претерпел Китай от рук европейцев в 19 и 20 веках; обожание Европы как своего учителя на протяжении всей современной своей истории; положительность чувств от уверенности в жизнеспособности китайской модели (неолиберализм отступает в Китае, там критически изучают и бросают вызов европейской традиции: от экономической модели до политических институтов) [31: 122].

Третья группа рассматривает Китай как социальное государство. Здесь исследуется исторический процесс трансформации отношений Китая с международными организациями, каким образом и до какой степени Китай стал вовлеченным в сотрудничество с международными организациями, занял более уступчивую позицию в отношении международных норм и был интегрирован в международную систему [32: 13].

\section{Внешняя политика Китая в 21 веке: философия глобальной державы}

В своей работе «Система Тянься: введение в философию мировой организации» в разделе «Не мир или несостоявшийся мир» китайский философ Чжао Тинян ставит теоретическую проблему отсутствия единого «мирового политического института» для решения глобальных политических проблем и обосновывает необходимость формулирования мировой философской концепции управления миром. Земной шар еще не стал чьим-либо миром и продолжает существовать в виде хаоса, поскольку нет по-настоящему связанного мирового сообщества, управляемого всеми принимаемым политическим институтом. Политически заброшенный, мир, в котором мы живем, является для нас не более чем географическим понятием. Недостаток политического единства означает, что «всеобщая политическая идентичность» еще не сформирована. Такой мир не возможен до тех пор, пока он не будет организован и управляем всемирным институтом, который будет иметь «глобальную политическую философию». Люди безуспешно стараются объединить мир, создавая мировые империи или союзы наций, пытаясь воплотить идею Канта о всеобщем мире или, в китайском варианте, достичь всеобщей гармонии между всеми народами. Неудачи этих попыток можно объяснить только отсутствием глобальной политической философии.
Политическая концепция «нации» хорошо всем знакома, потому, что все знают, что нужно делать для государства-нации. Однако это не происходит с политической формой «мир». Главная проблема сегодня заключается в том, что «несостоявшийся мир противопоставлен несостоявшимся государствам» [33: 14].

Рассуждая о «китайской мечте», или, другими словами, о Китае будущего, который не отделим от глобального мира, Чжао Тинян утверждает, что мир демонстрирует развивающуюся глобальную идентичность. Национальная мечта, говорит он, не будет работать хорошо, пока она всерьез не учтет глобальные условия. Мечта современности всегда будет встречаться с глобальными вызовами и, поэтому, она должна быть трансформирована в мечту о формировании глобальности. Одним из фундаментальных изменений в глобальное время неизбежность и необходимость взаимозависимости всех наций, всех народов и всех стран. Это создает новые онтологические условия для сосуществования, своего рода симбиоз, при котором выживание и учёт интересов всех стран и всех народов становятся возможными. Требуется внесение изменений в правила игры, продвинутые стратегии и основные концепции или ценности этого мира [33: 139]. Национальная мечта должна быть связана с глобальной мечтой, а мир совместимости должен вовремя заменить мир конкуренции, пока мы не создали мир беспорядка, К сожалению, мир движется к беспорядку. Финансовый кризис, протекционистские экономические войны, беспорядки в Северной Африке и Ближнем Востоке, распространение ядерного оружия и терроризма, опасность изменения климата и загрязнение - результаты нынешнего времени, которое изобилует жадностью, враждой и эксплуатацией. Современная мечта не уйдет слишком далеко, поскольку не может справиться с их карающими последствиями. Поэтому миру нужна глобальная мечта [33: 140].

По мнению Чжао Тиняна, обновленная система «Поднебесная» и рациональные отношения могут быть универсальными идеалами, которые приведут к совместимому и мирному миру. Рациональность отношений сможет снизить большое количество враждебной конкуренции и развитой современной индивидуальной рациональности, направленной на максимизацию личной выгоды. А система «Поднебесная» сможет сделать мир с обновленным и совершенным вечным миром, основанном на глобальных условиях мультицивилизаций, более охватывающим, чем кантианские 
условия для мира. Если совместимый мир «Поднебесной» станет однажды доступным, надеется Чжао Тинян, это будет мировой мечтой больше, чем китайская мечта [33: 141].

Китайские ученые стараются сформулировать перспективы Китая в основных философских понятиях. Вице-президент Академии современных международных отношений Ван Цзайбань говорит о том, что Китай в 21 веке находится в «периоде стратегических возможностей» ("the strategic opportunity period", SOP), измеряющийся в характеристиках времени, пространства и ценностей. Еще 16 съезд КПК (8-15 ноября 2002) определил это время: десять или двадцать лет 21 века. В пространственном отношении он носит глобальный характер и оказывает влияние на ход всей истории. Под ценностями понимается позитивное воздействие на конкретные области в течение длительного времени. Таким образом, период стратегических возможностей - это «пространственные и временные тренды, которые оказывают всеобщее позитивное воздействие на будущее и судьбу в конкретных областях». Характеристиками этого периода являются: объективность (пространственные и временные тренды, которые формируются взаимодействием многих факторов; «нравятся они нам или нет, но это реальность»), включенность (так как эти тренды существуют объективно, они не могут быть «иксклюзивны» в плане получения выгоды только для одной страны; они предоставля- ют возможность всем странам) и относительность (помимо возможностей всегда присутствуют вызовы, позитивные благоприятные факторы не избавлены для некоторых стран от негативных; вызовы могут измениться от «угроз» к «возможностям») [34: 2].

Важными чертами современного международного порядка, по мнению китайских экспертов, является (1) смещение власти внутри западного мира от США к Германии, (2) невозможность ни одной страны сформировать свой глобальный порядок, поэтому мир движется в сторону многополярности, (3) страна, желающая играть лидирующую роль в каком-либо регионе, должна обладать системой главных ценностей. Они также считают, что решающим фактором в подъеме Советского Союза была ценностная система социализма. Россия сейчас восстанавливается, но ее возрождение как глобальной державы нуждается в системе ценностей с глобальным влиянием. Европейский Союз играет роль «нормативной державы». США продолжают создавать «свободный мир». В глазах мирового сообщества Китай формирует образ миролюбивой нации, поэтому выдвигает много идей, в центре которых мир (мирное сосуществование, мирное развитие, гармоничный мир) [35: 6, 7]. Это фактически те глобальные ценности, на которых Китай строит сейчас свой новый международный порядок, главной чертой которого, как представляется в Пекине, будет его мирный характер.

\section{Библиография:}

1. Zhao Tingyang. All-Under-Heaven and Methodological Relationism. An Old Story and New World Peace, in Contemporary Chinese Political Thought: Debates and Perspectives. Edited by Fred Dallmayr and Zhao Tingyang. Kentucky: The University Press of Kentucky. 2012. 283 p.

2. Chen Li. Zhanlue dili lun [Strategical Geography]. Beijing: Jiefangjun chubanshe. 1990. 349 p.

3. Diyuan zhanlue yu daguo anquan [Geostrategy and Security of Great Power]. Nigula Chaqiang, Shen Weilie, Pu Ning zhu. Beijing: Jiefangjun chubanshe. 2012. 374 p.

4. Zhao Tingyang. The "China Dream" in Question / "Economic and Political Studies" 2014. Vol. 2. No.1.

5. Wendt, Alexander. Social Theory of International Relations. Cambridge: Cambridge University Press. 1999. 429 p.

6. Li Kaisheng. Lijie Zhongguo waijiao (1949-2009): minzu fuxing jincheng de guojia shenfeng tanqiu [Identity, National Revival and China's Foreign Strategy (1949-2009)]. Beijing: Zhongguo shehui kexue chubanshe. 2011. 226 p.

7. Zhang Zhirong. Zhongguo duiwai guanxi xinlun: diyuan zhengzhi yu linbang waijiao yanjiu [Chinese Foreign Relations: New Perspectives on Geopolitics and the Good Neighbour Policy]. Beijing: Guji chubanshe. 2008. 434 p.

8. Lou Yaoliang. Diyuan zhengzhi yu Zhongguo guofang zhanlue [Geopolitics and China's Strategy of National Defence]. Tianjing: Tianjing Renmin chubanshe. 2002. 287 p.

9. Ye Zicheng. Luquan fazhan yu daguo xingshuai: diyuanzhengzhi huangjing yu Zhongguo heping fazhande diyuan zhanlue xuanze. [Development of Land Power and Great Power's Rise and Fall: the Environment of Geopolitics and the Choice of Geostrategy of China's Peaceful Development]. Beijing. Xinxi chubanshe. 2007. 336 p.

10. Zhongguo "Zouchuqu" zhanlue shi nian huigu: chengjiu yu tiaozhan / "Xiangdai guoji guanxi" 2011 nian di 8 qi [Ten Years of China's "Go Abroad" Strategy: Results and Challenges / "Contemporary International Relations"].

11. Wang Wei. Diyuan zhengzhi yu Zhongguo guojia anquan [Geopolitics and National Security of China]. Beijing: Junshi yiwen chubanshe. 2009.

12. Zhang Shiping. Zhongguo haiquan [Sea Power of China]. Beijing: Renmin ribao chubanshe. 2009. 347 p.

13. Lin Hongyu. From Passive to Active / «Contemporary International Relations». 2014. Vol. 24 No. 4. 


\section{Международные отношения / International Relations / № 3 / 2015}

14. Guoji guanxi shiyong shouce. Huan Rihan, Yao Yufei zhubian. [Practical Handbook of International Relations. Edited by Huan Rihan, Yao Yufei]. Tianjing: Tianjing renmin chubanshe. 2013. $311 \mathrm{p}$.

15. Ye Zicheng. Zhongguo da zhanlue [China's Grand Strategy]. Beijing: Zhongguo shehui kexue chubanshe. 2003. 442 p.

16. Chu Shulong, Jin Wei. Zhongguo waijiao zhanlue he zhengce [China's Foreign Strategy and Policy]. Beijing: Shishi chubanshe. 2008. $495 \mathrm{p}$.

17. Qin Yaqing (ed.). Guoji tixi yu Zhongguo waijiao [International System and China's Diplomacy]. Beijing: Shiji zhishi chubanshe. 2009. $401 \mathrm{p}$.

18. Wu Xiaodi. Zhongguo diyuan zhengzhi zhuangxin [The turn of China's Geopolitics]. Beijing: Zhongguo da baike quanshu chubanshe. 2006. 273 p.

19. Fu Mengzi. China's International Influence / “Contemporary International Relations”. 2011. Vol. 21. No. 2.

20. Niu Jun. «Lianmeng yu zhanzheng»: lengzhan shidai de Zhongguo zhanlue juece jiqi houguo / «Shijie jingji yu zhengzhi». 2014. Di 6 qi [Coalitions and Wars: China's Strategic Choices in the Cold War Era and its Consequences / "World Economy and Policy"].

21. Mao Tszedun. Izbranyye proizvedeniya. Tom 4. Izdaniye literatury na inostrannykh yazykakh [Mao Zedong. Selected Works]. Pekin. 1969.

22. Wuthnow, Joel. Chinese Diplomacy and the UN Security Council: Beyond the veto. London \& New York: Routledge. 2013. (Electronic edition). 220 p.

23. Hu Shuxiang (ed.). Zhongguo waijiao yu guoji fazhan zhanlue yanjiu. [The Diplomacy of China and the Strategy of International Development]. Beijing: Zhongguo renmin daxue chubanshe. 2009. $351 \mathrm{p}$.

24. Li Baojun. Dangdai Zhongguo waijiao gailun [Introduction to China's Diplomacy]. Beijing: Zhongguo renmin daxue chubanshe. 2005. 275 p.

25. Xi Laiwang. Waijiao moulue: zai zhanxin de shijie geju zhong yunchou weiwo [Diplomatic Stratagems: Development of Strategic Blueprint in the Context of Newly Formated World Structure]. Beijing: Hongqi chubanshe. 1996. 462 p.

26. Zhang Baohui. Chinese Foreign Policy in Transition: Trends and Implications / Journal of Current Chinese Affairs. 2010. Vol. 35. No. 2.

27. Wang Honggang. How Can the U.S. and China Build a "Cooperative Partnership"? / "Contemporary International Relations". 2011. Vol. 21, No. 4.

28. Yuan Peng. On the Changes in the International Order / «Contemporary International Relations». 2014. Vol. 24 No. 4.

29. Le Yucheng. Thoughts on China's Diplomacy in a Changing World / «Contemporary International Relations». 2012. Vol. 22 No. 5.

30. Pan Zhongqi (ed.). Conceptual Gaps in China-EU Relations: Global Governance, Human Rights and Strategic Partnerships. Palgrave Macmillan. 2012. 267 p.

31. Huang Jing. The Clash in Public Opinion between Europe and China: What, How and Why / «Contemporary International Relations». 2010. Vol. 20 No. 2.

32. China and the International System: Becoming a World Power. Edited by Huang Xiaoming, Rober Patman. London \& New York: Routledge. 2013. 229 p.

33. Zhao Tingyang. Tianxia tixi: shijie zhidu zhexue daolun [The Tianxia System: An Introduction to the Philosophy of the World Institution]. Beijing: Zhongguo renmin chubanshe. 2011.271 p.

34. Wang Zaibang. On Connotations and Conditions in China's New SOP / "Contemporary International Relations". 2013. Vol. 23, No. 2.

35. Su Changhe. Evolution of International Order / “Contemporary International Relations”. 2014. Vol. 24 No. 4.

36. China and the International System: Becoming a World Power. Edited by Huang Xiaoming, Rober Patman. London \& New York: Routledge. 2013. 229 p.

37. Huang Jing. The Clash in Public Opinion between Europe and China: What, How and Why / «Contemporary International Relations». 2010. Vol. 20 No. 2.

38. Pan Zhongqi (ed.). Conceptual Gaps in China-EU Relations: Global Governance, Human Rights and Strategic Partnerships. Palgrave Macmillan. 2012. 267 p.

39. Wang Honggang. How Can the U.S. and China Build a "Cooperative Partnership"? / "Contemporary International Relations". 2011. Vol. 21, No. 4.

40. Yuan Peng. On the Changes in the International Order / «Contemporary International Relations». 2014. Vol. 24 No. 4.

41. Zhang Baohui. Chinese Foreign Policy in Transition: Trends and Implications / Journal of Current Chinese Affairs. 2010. Vol. 35. No. 2.

42. Xi Laiwang. Waijiao moulue: zai zhanxin de shijie geju zhong yunchou weiwo [Diplomatic Stratagems: Development of Strategic Blueprint in the Context of Newly Formated World Structure]. Beijing: Hongqi chubanshe. 1996. 462 p.

43. Wuthnow, Joel. Chinese Diplomacy and the UN Security Council: Beyond the veto. London \& New York: Routledge. 2013. (Electronic edition). $220 \mathrm{p}$.

44. Hu Shuxiang (ed.). Zhongguo waijiao yu guoji fazhan zhanlue yanjiu. [The Diplomacy of China and the Strategy of International Development]. Beijing: Zhongguo renmin daxue chubanshe. 2009. 351 p.

45. Mao Tszedun. Izbranyye proizvedeniya. Tom 4. Izdaniye literatury na inostrannykh yazykakh [Mao Zedong. Selected Works]. Pekin. 1969.

46. Fu Mengzi. China's International Influence / “Contemporary International Relations”. 2011. Vol. 21. No. 2.

47. Qin Yaqing (ed.). Guoji tixi yu Zhongguo waijiao [International System and China's Diplomacy]. Beijing: Shiji zhishi chubanshe. 2009. 401 p. 


\section{Мировая политика / World Politics}

48. Chu Shulong, Jin Wei. Zhongguo waijiao zhanlue he zhengce [China's Foreign Strategy and Policy]. Beijing: Shishi chubanshe. 2008. $495 \mathrm{p}$.

49. Guoji guanxi shiyong shouce. Huan Rihan, Yao Yufei zhubian. [Practical Handbook of International Relations. Edited by Huan Rihan, Yao Yufei]. Tianjing: Tianjing renmin chubanshe. 2013. 311 p.

50. Lin Hongyu. From Passive to Active / «Contemporary International Relations». 2014. Vol. 24 No. 4.

51. Zhang Shiping. Zhongguo haiquan [Sea Power of China]. Beijing: Renmin ribao chubanshe. 2009. 347 p.

52. Wang Wei. Diyuan zhengzhi yu Zhongguo guojia anquan [Geopolitics and National Security of China]. Beijing: Junshi yiwen chubanshe. 2009.

53. Zhongguo "Zouchuqu" zhanlue shi nian huigu: chengjiu yu tiaozhan / "Xiangdai guoji guanxi" 2011 nian di 8 qi [Ten Years of China's "Go Abroad" Strategy: Results and Challenges / "Contemporary International Relations"].

54. Ye Zicheng. Luquan fazhan yu daguo xingshuai: diyuanzhengzhi huangjing yu Zhongguo heping fazhande diyuan zhanlue xuanze. [Development of Land Power and Great Power's Rise and Fall: the Environment of Geopolitics and the Choice of Geostrategy of China's Peaceful Development]. Beijing. Xinxi chubanshe. 2007. 336 p.

55. Lou Yaoliang. Diyuan zhengzhi yu Zhongguo guofang zhanlue [Geopolitics and China's Strategy of National Defence]. Tianjing: Tianjing Renmin chubanshe. 2002. 287 p.

56. Zhang Zhirong. Zhongguo duiwai guanxi xinlun: diyuan zhengzhi yu linbang waijiao yanjiu [Chinese Foreign Relations: New Perspectives on Geopolitics and the Good Neighbour Policy]. Beijing: Guji chubanshe. 2008. 434 p.

57. Wendt, Alexander. Social Theory of International Relations. Cambridge: Cambridge University Press. 1999.429 p.

58. Zhao Tingyang. The "China Dream" in Question / "Economic and Political Studies" 2014. Vol. 2. No.1.

59. Diyuan zhanlue yu daguo anquan [Geostrategy and Security of Great Power]. Nigula Chaqiang, Shen Weilie, Pu Ning zhu. Beijing: Jiefangjun chubanshe. 2012. 374 p.

60. Chen Li. Zhanlue dili lun [Strategical Geography]. Beijing: Jiefangjun chubanshe. 1990. 349 p.

61. Zhao Tingyang. All-Under-Heaven and Methodological Relationism. An Old Story and New World Peace, in Contemporary Chinese Political Thought: Debates and Perspectives. Edited by Fred Dallmayr and Zhao Tingyang. Kentucky: The University Press of Kentucky. 2012. 283 p.

62. Zhao Tingyang. Tianxia tixi: shijie zhidu zhexue daolun [The Tianxia System: An Introduction to the Philosophy of the World Institution]. Beijing: Zhongguo renmin chubanshe. 2011. $271 \mathrm{p}$.

63. Wang Zaibang. On Connotations and Conditions in China's New SOP / "Contemporary International Relations". 2013. Vol. 23, No. 2.

64. Su Changhe. Evolution of International Order / "Contemporary International Relations”. 2014. Vol. 24 No. 4.

65. China and the International System: Becoming a World Power. Edited by Huang Xiaoming, Rober Patman. London \& New York: Routledge. 2013. 229 p.

66. Huang Jing. The Clash in Public Opinion between Europe and China: What, How and Why / «Contemporary International Relations». 2010. Vol. 20 No. 2.

67. Pan Zhongqi (ed.). Conceptual Gaps in China-EU Relations: Global Governance, Human Rights and Strategic Partnerships. Palgrave Macmillan. 2012. 267 p.

68. Wang Honggang. How Can the U.S. and China Build a "Cooperative Partnership"? / "Contemporary International Relations". 2011. Vol. 21, No. 4.

69. Yuan Peng. On the Changes in the International Order / «Contemporary International Relations». 2014. Vol. 24 No. 4.

70. Zhang Baohui. Chinese Foreign Policy in Transition: Trends and Implications / Journal of Current Chinese Affairs. 2010. Vol. 35. No. 2.

71. Xi Laiwang. Waijiao moulue: zai zhanxin de shijie geju zhong yunchou weiwo [Diplomatic Stratagems: Development of Strategic Blueprint in the Context of Newly Formated World Structure]. Beijing: Hongqi chubanshe. 1996.462 p.

72. Wuthnow, Joel. Chinese Diplomacy and the UN Security Council: Beyond the veto. London \& New York: Routledge. 2013. (Electronic edition). $220 \mathrm{p}$.

73. Hu Shuxiang (ed.). Zhongguo waijiao yu guoji fazhan zhanlue yanjiu. [The Diplomacy of China and the Strategy of International Development]. Beijing: Zhongguo renmin daxue chubanshe. 2009. 351 p.

74. Mao Tszedun. Izbranyye proizvedeniya. Tom 4. Izdaniye literatury na inostrannykh yazykakh [Mao Zedong. Selected Works]. Pekin. 1969.

75. Fu Mengzi. China's International Influence / “Contemporary International Relations”. 2011. Vol. 21. No. 2.

76. Qin Yaqing (ed.). Guoji tixi yu Zhongguo waijiao [International System and China's Diplomacy]. Beijing: Shiji zhishi chubanshe. 2009. $401 \mathrm{p}$.

77. Chu Shulong, Jin Wei. Zhongguo waijiao zhanlue he zhengce [China's Foreign Strategy and Policy]. Beijing: Shishi chubanshe. 2008. 495 p.

78. Guoji guanxi shiyong shouce. Huan Rihan, Yao Yufei zhubian. [Practical Handbook of International Relations. Edited by Huan Rihan, Yao Yufei]. Tianjing: Tianjing renmin chubanshe. 2013. 311 p.

79. Lin Hongyu. From Passive to Active / «Contemporary International Relations». 2014. Vol. 24 No. 4.

80. Zhang Shiping. Zhongguo haiquan [Sea Power of China]. Beijing: Renmin ribao chubanshe. 2009. 347 p.

81. Wang Wei. Diyuan zhengzhi yu Zhongguo guojia anquan [Geopolitics and National Security of China]. Beijing: Junshi yiwen chubanshe. 2009.

82. Zhongguo "Zouchuqu" zhanlue shi nian huigu: chengjiu yu tiaozhan / "Xiangdai guoji guanxi” 2011 nian di 8 qi [Ten Years of China's “Go Abroad" Strategy: Results and Challenges / “Contemporary International Relations”]. 


\section{Международные отношения / International Relations / № 3 / 2015}

83. Ye Zicheng. Luquan fazhan yu daguo xingshuai: diyuanzhengzhi huangjing yu Zhongguo heping fazhande diyuan zhanlue xuanze. [Development of Land Power and Great Power's Rise and Fall: the Environment of Geopolitics and the Choice of Geostrategy of China's Peaceful Development]. Beijing. Xinxi chubanshe. 2007. 336 p.

84. Lou Yaoliang. Diyuan zhengzhi yu Zhongguo guofang zhanlue [Geopolitics and China's Strategy of National Defence]. Tianjing: Tianjing Renmin chubanshe. 2002. 287 p.

85. Zhang Zhirong. Zhongguo duiwai guanxi xinlun: diyuan zhengzhi yu linbang waijiao yanjiu [Chinese Foreign Relations: New Perspectives on Geopolitics and the Good Neighbour Policy]. Beijing: Guji chubanshe. 2008. 434 p.

86. Wendt, Alexander. Social Theory of International Relations. Cambridge: Cambridge University Press. 1999. 429 p.

87. Zhao Tingyang. The "China Dream" in Question / "Economic and Political Studies" 2014. Vol. 2. No.1.

88. Diyuan zhanlue yu daguo anquan [Geostrategy and Security of Great Power]. Nigula Chaqiang, Shen Weilie, Pu Ning zhu. Beijing: Jiefangjun chubanshe. 2012. 374 p.

89. Chen Li. Zhanlue dili lun [Strategical Geography]. Beijing: Jiefangjun chubanshe. 1990. 349 p.

90. Zhao Tingyang. All-Under-Heaven and Methodological Relationism. An Old Story and New World Peace, in Contemporary Chinese Political Thought: Debates and Perspectives. Edited by Fred Dallmayr and Zhao Tingyang. Kentucky: The University Press of Kentucky. 2012. 283 p.

91. Zhao Tingyang. Tianxia tixi: shijie zhidu zhexue daolun [The Tianxia System: An Introduction to the Philosophy of the World Institution]. Beijing: Zhongguo renmin chubanshe. 2011. 271 p.

92. Wang Zaibang. On Connotations and Conditions in China's New SOP / "Contemporary International Relations". 2013. Vol. 23, No. 2.

93. Su Changhe. Evolution of International Order / "Contemporary International Relations". 2014. Vol. 24 No. 4.

94. China and the International System: Becoming a World Power. Edited by Huang Xiaoming, Rober Patman. London \& New York: Routledge. 2013. 229 p.

95. Huang Jing. The Clash in Public Opinion between Europe and China: What, How and Why / «Contemporary International Relations». 2010. Vol. 20 No. 2.

96. Pan Zhongqi (ed.). Conceptual Gaps in China-EU Relations: Global Governance, Human Rights and Strategic Partnerships. Palgrave Macmillan. 2012. 267 p.

97. Wang Honggang. How Can the U.S. and China Build a "Cooperative Partnership"? / "Contemporary International Relations". 2011. Vol. 21, No. 4.

98. Yuan Peng. On the Changes in the International Order / «Contemporary International Relations». 2014. Vol. 24 No. 4.

99. Zhang Baohui. Chinese Foreign Policy in Transition: Trends and Implications / Journal of Current Chinese Affairs. 2010. Vol. 35. No. 2.

100. Xi Laiwang. Waijiao moulue: zai zhanxin de shijie geju zhong yunchou weiwo [Diplomatic Stratagems: Development of Strategic Blueprint in the Context of Newly Formated World Structure]. Beijing: Hongqi chubanshe. 1996. 462 p.

101. Wuthnow, Joel. Chinese Diplomacy and the UN Security Council: Beyond the veto. London \& New York: Routledge. 2013. (Electronic edition). $220 \mathrm{p}$.

102. Hu Shuxiang (ed.). Zhongguo waijiao yu guoji fazhan zhanlue yanjiu. [The Diplomacy of China and the Strategy of International Development]. Beijing: Zhongguo renmin daxue chubanshe. 2009. 351 p.

103. Mao Tszedun. Izbranyye proizvedeniya. Tom 4. Izdaniye literatury na inostrannykh yazykakh [Mao Zedong. Selected Works]. Pekin. 1969.

104. Fu Mengzi. China's International Influence / “Contemporary International Relations”. 2011. Vol. 21. No. 2.

105. Qin Yaqing (ed.). Guoji tixi yu Zhongguo waijiao [International System and China's Diplomacy]. Beijing: Shiji zhishi chubanshe. 2009. 401 p.

106. Chu Shulong, Jin Wei. Zhongguo waijiao zhanlue he zhengce [China's Foreign Strategy and Policy]. Beijing: Shishi chubanshe. 2008. 495 p.

107. Guoji guanxi shiyong shouce. Huan Rihan, Yao Yufei zhubian. [Practical Handbook of International Relations. Edited by Huan Rihan, Yao Yufei]. Tianjing: Tianjing renmin chubanshe. 2013. 311 p.

108. Lin Hongyu. From Passive to Active / «Contemporary International Relations». 2014. Vol. 24 No. 4.

109. Zhang Shiping. Zhongguo haiquan [Sea Power of China]. Beijing: Renmin ribao chubanshe. 2009. 347 p.

110. Wang Wei. Diyuan zhengzhi yu Zhongguo guojia anquan [Geopolitics and National Security of China]. Beijing: Junshi yiwen chubanshe. 2009.

111. Zhongguo "Zouchuqu" zhanlue shi nian huigu: chengjiu yu tiaozhan / "Xiangdai guoji guanxi" 2011 nian di 8 qi [Ten Years of China's "Go Abroad" Strategy: Results and Challenges / "Contemporary International Relations"].

112. Ye Zicheng. Luquan fazhan yu daguo xingshuai: diyuanzhengzhi huangjing yu Zhongguo heping fazhande diyuan zhanlue xuanze. [Development of Land Power and Great Power's Rise and Fall: the Environment of Geopolitics and the Choice of Geostrategy of China's Peaceful Development]. Beijing. Xinxi chubanshe. 2007. 336 p.

113. Lou Yaoliang. Diyuan zhengzhi yu Zhongguo guofang zhanlue [Geopolitics and China's Strategy of National Defence]. Tianjing: Tianjing Renmin chubanshe. 2002. 287 p.

114. Zhang Zhirong. Zhongguo duiwai guanxi xinlun: diyuan zhengzhi yu linbang waijiao yanjiu [Chinese Foreign Relations: New Perspectives on Geopolitics and the Good Neighbour Policy]. Beijing: Guji chubanshe. 2008. 434 p.

115. Wendt, Alexander. Social Theory of International Relations. Cambridge: Cambridge University Press. 1999.429 p.

116. Zhao Tingyang. The "China Dream" in Question / "Economic and Political Studies" 2014. Vol. 2. No.1. 


\section{Мировая политика / World Politics}

117. Diyuan zhanlue yu daguo anquan [Geostrategy and Security of Great Power]. Nigula Chaqiang, Shen Weilie, Pu Ning zhu. Beijing: Jiefangjun chubanshe. 2012. 374 p.

118. Chen Li. Zhanlue dili lun [Strategical Geography]. Beijing: Jiefangjun chubanshe. 1990. 349 p.

119. Zhao Tingyang. All-Under-Heaven and Methodological Relationism. An Old Story and New World Peace, in Contemporary Chinese Political Thought: Debates and Perspectives. Edited by Fred Dallmayr and Zhao Tingyang. Kentucky: The University Press of Kentucky. 2012. 283 p.

120. Zhao Tingyang. Tianxia tixi: shijie zhidu zhexue daolun [The Tianxia System: An Introduction to the Philosophy of the World Institution]. Beijing: Zhongguo renmin chubanshe. 2011. 271 p.

121. Wang Zaibang. On Connotations and Conditions in China's New SOP / "Contemporary International Relations". 2013. Vol. 23, No. 2.

122. Su Changhe. Evolution of International Order / “Contemporary International Relations”. 2014. Vol. 24 No. 4.

123. Манойло А.В. Информационно-психологические технологии разрешения современных конфликтов. // Власть. 2008. - №5. - C.27-30.

124. Будаев А.В. Присутствие России в Бразилии: «мягкая сила» в двусторонних отношениях. // Латинская Америка. 2013. № 5. С. 61-65.

\section{References (transliterated):}

1. Zhao Tingyang. All-Under-Heaven and Methodological Relationism. An Old Story and New World Peace, in Contemporary Chinese Political Thought: Debates and Perspectives. Edited by Fred Dallmayr and Zhao Tingyang. Kentucky: The University Press of Kentucky. 2012. 283 p.

2. Chen Li. Zhanlue dili lun [Strategical Geography]. Beijing: Jiefangjun chubanshe. 1990. 349 p.

3. Diyuan zhanlue yu daguo anquan [Geostrategy and Security of Great Power]. Nigula Chaqiang, Shen Weilie, Pu Ning zhu. Beijing: Jiefangjun chubanshe. 2012. 374 p.

4. Zhao Tingyang. The "China Dream" in Question / "Economic and Political Studies" 2014. Vol. 2. No.1.

5. Wendt, Alexander. Social Theory of International Relations. Cambridge: Cambridge University Press. 1999. 429 p.

6. Li Kaisheng. Lijie Zhongguo waijiao (1949-2009): minzu fuxing jincheng de guojia shenfeng tanqiu [Identity, National Revival and China's Foreign Strategy (1949-2009)]. Beijing: Zhongguo shehui kexue chubanshe. 2011. 226 p.

7. Zhang Zhirong. Zhongguo duiwai guanxi xinlun: diyuan zhengzhi yu linbang waijiao yanjiu [Chinese Foreign Relations: New Perspectives on Geopolitics and the Good Neighbour Policy]. Beijing: Guji chubanshe. 2008. 434 p.

8. Lou Yaoliang. Diyuan zhengzhi yu Zhongguo guofang zhanlue [Geopolitics and China's Strategy of National Defence]. Tianjing: Tianjing Renmin chubanshe. 2002. 287 p.

9. Ye Zicheng. Luquan fazhan yu daguo xingshuai: diyuanzhengzhi huangjing yu Zhongguo heping fazhande diyuan zhanlue xuanze. [Development of Land Power and Great Power's Rise and Fall: the Environment of Geopolitics and the Choice of Geostrategy of China's Peaceful Development]. Beijing. Xinxi chubanshe. 2007. 336 p.

10. Zhongguo "Zouchuqu" zhanlue shi nian huigu: chengjiu yu tiaozhan / "Xiangdai guoji guanxi" 2011 nian di 8 qi [Ten Years of China's "Go Abroad" Strategy: Results and Challenges / "Contemporary International Relations"].

11. Wang Wei. Diyuan zhengzhi yu Zhongguo guojia anquan [Geopolitics and National Security of China]. Beijing: Junshi yiwen chubanshe. 2009.

12. Zhang Shiping. Zhongguo haiquan [Sea Power of China]. Beijing: Renmin ribao chubanshe. 2009. 347 p.

13. Lin Hongyu. From Passive to Active / «Contemporary International Relations». 2014. Vol. 24 No. 4.

14. Guoji guanxi shiyong shouce. Huan Rihan, Yao Yufei zhubian. [Practical Handbook of International Relations. Edited by Huan Rihan, Yao Yufei]. Tianjing: Tianjing renmin chubanshe. 2013. 311 p.

15. Ye Zicheng. Zhongguo da zhanlue [China's Grand Strategy]. Beijing: Zhongguo shehui kexue chubanshe. 2003.442 p.

16. Chu Shulong, Jin Wei. Zhongguo waijiao zhanlue he zhengce [China's Foreign Strategy and Policy]. Beijing: Shishi chubanshe. 2008. 495 p.

17. Qin Yaqing (ed.). Guoji tixi yu Zhongguo waijiao [International System and China's Diplomacy]. Beijing: Shiji zhishi chubanshe. 2009. 401 p.

18. Wu Xiaodi. Zhongguo diyuan zhengzhi zhuangxin [The turn of China's Geopolitics]. Beijing: Zhongguo da baike quanshu chubanshe. 2006. 273 p.

19. Fu Mengzi. China's International Influence / “Contemporary International Relations”. 2011. Vol. 21. No. 2.

20. Niu Jun. «Lianmeng yu zhanzheng»: lengzhan shidai de Zhongguo zhanlue juece jiqi houguo / «Shijie jingji yu zhengzhi». 2014. Di 6 qi [Coalitions and Wars: China's Strategic Choices in the Cold War Era and its Consequences / "World Economy and Policy"].

21. Mao Tszedun. Izbranyye proizvedeniya. Tom 4. Izdaniye literatury na inostrannykh yazykakh [Mao Zedong. Selected Works]. Pekin. 1969.

22. Wuthnow, Joel. Chinese Diplomacy and the UN Security Council: Beyond the veto. London \& New York: Routledge. 2013. (Electronic edition). 220 p.

23. Hu Shuxiang (ed.). Zhongguo waijiao yu guoji fazhan zhanlue yanjiu. [The Diplomacy of China and the Strategy of International Development]. Beijing: Zhongguo renmin daxue chubanshe. 2009. $351 \mathrm{p}$.

24. Li Baojun. Dangdai Zhongguo waijiao gailun [Introduction to China's Diplomacy]. Beijing: Zhongguo renmin daxue chubanshe. 2005. 275 p. 


\section{Международные отношения / International Relations / № 3 / 2015}

25. Xi Laiwang. Waijiao moulue: zai zhanxin de shijie geju zhong yunchou weiwo [Diplomatic Stratagems: Development of Strategic Blueprint in the Context of Newly Formated World Structure]. Beijing: Hongqi chubanshe. 1996. 462 p.

26. Zhang Baohui. Chinese Foreign Policy in Transition: Trends and Implications / Journal of Current Chinese Affairs. 2010. Vol. 35. No. 2.

27. Wang Honggang. How Can the U.S. and China Build a "Cooperative Partnership"? / "Contemporary International Relations". 2011. Vol. 21, No. 4.

28. Yuan Peng. On the Changes in the International Order / «Contemporary International Relations». 2014. Vol. 24 No. 4.

29. Le Yucheng. Thoughts on China's Diplomacy in a Changing World / «Contemporary International Relations». 2012. Vol. 22 No. 5.

30. Pan Zhongqi (ed.). Conceptual Gaps in China-EU Relations: Global Governance, Human Rights and Strategic Partnerships. Palgrave Macmillan. 2012. 267 p.

31. Huang Jing. The Clash in Public Opinion between Europe and China: What, How and Why / «Contemporary International Relations». 2010. Vol. 20 No. 2.

32. China and the International System: Becoming a World Power. Edited by Huang Xiaoming, Rober Patman. London \& New York: Routledge. 2013. 229 p.

33. Zhao Tingyang. Tianxia tixi: shijie zhidu zhexue daolun [The Tianxia System: An Introduction to the Philosophy of the World Institution]. Beijing: Zhongguo renmin chubanshe. 2011. 271 p.

34. Wang Zaibang. On Connotations and Conditions in China's New SOP / “Contemporary International Relations”. 2013. Vol. 23, No. 2.

35. Su Changhe. Evolution of International Order / "Contemporary International Relations". 2014. Vol. 24 No. 4.

36. China and the International System: Becoming a World Power. Edited by Huang Xiaoming, Rober Patman. London \& New York: Routledge. 2013. 229 p.

37. Huang Jing. The Clash in Public Opinion between Europe and China: What, How and Why / «Contemporary International Relations». 2010. Vol. 20 No. 2.

38. Pan Zhongqi (ed.). Conceptual Gaps in China-EU Relations: Global Governance, Human Rights and Strategic Partnerships. Palgrave Macmillan. 2012. 267 p.

39. Wang Honggang. How Can the U.S. and China Build a "Cooperative Partnership"? / "Contemporary International Relations". 2011. Vol. 21, No. 4.

40. Yuan Peng. On the Changes in the International Order / «Contemporary International Relations». 2014. Vol. 24 No. 4.

41. Zhang Baohui. Chinese Foreign Policy in Transition: Trends and Implications / Journal of Current Chinese Affairs. 2010. Vol. 35. No. 2.

42. Xi Laiwang. Waijiao moulue: zai zhanxin de shijie geju zhong yunchou weiwo [Diplomatic Stratagems: Development of Strategic Blueprint in the Context of Newly Formated World Structure]. Beijing: Hongqi chubanshe. 1996. 462 p.

43. Wuthnow, Joel. Chinese Diplomacy and the UN Security Council: Beyond the veto. London \& New York: Routledge. 2013. (Electronic edition). $220 \mathrm{p}$.

44. Hu Shuxiang (ed.). Zhongguo waijiao yu guoji fazhan zhanlue yanjiu. [The Diplomacy of China and the Strategy of International Development]. Beijing: Zhongguo renmin daxue chubanshe. 2009. $351 \mathrm{p}$.

45. Mao Tszedun. Izbranyye proizvedeniya. Tom 4. Izdaniye literatury na inostrannykh yazykakh [Mao Zedong. Selected Works]. Pekin. 1969.

46. Fu Mengzi. China's International Influence / “Contemporary International Relations”. 2011. Vol. 21. No. 2.

47. Qin Yaqing (ed.). Guoji tixi yu Zhongguo waijiao [International System and China's Diplomacy]. Beijing: Shiji zhishi chubanshe. 2009. 401 p.

48. Chu Shulong, Jin Wei. Zhongguo waijiao zhanlue he zhengce [China's Foreign Strategy and Policy]. Beijing: Shishi chubanshe. 2008. 495 p.

49. Guoji guanxi shiyong shouce. Huan Rihan, Yao Yufei zhubian. [Practical Handbook of International Relations. Edited by Huan Rihan, Yao Yufei]. Tianjing: Tianjing renmin chubanshe. 2013. 311 p.

50. Lin Hongyu. From Passive to Active / «Contemporary International Relations». 2014. Vol. 24 No. 4.

51. Zhang Shiping. Zhongguo haiquan [Sea Power of China]. Beijing: Renmin ribao chubanshe. 2009. 347 p.

52. Wang Wei. Diyuan zhengzhi yu Zhongguo guojia anquan [Geopolitics and National Security of China]. Beijing: Junshi yiwen chubanshe. 2009.

53. Zhongguo "Zouchuqu" zhanlue shi nian huigu: chengjiu yu tiaozhan / "Xiangdai guoji guanxi" 2011 nian di 8 qi [Ten Years of China's "Go Abroad" Strategy: Results and Challenges / "Contemporary International Relations"].

54. Ye Zicheng. Luquan fazhan yu daguo xingshuai: diyuanzhengzhi huangjing yu Zhongguo heping fazhande diyuan zhanlue xuanze. [Development of Land Power and Great Power's Rise and Fall: the Environment of Geopolitics and the Choice of Geostrategy of China's Peaceful Development]. Beijing. Xinxi chubanshe. 2007. 336 p.

55. Lou Yaoliang. Diyuan zhengzhi yu Zhongguo guofang zhanlue [Geopolitics and China's Strategy of National Defence]. Tianjing: Tianjing Renmin chubanshe. 2002. 287 p.

56. Zhang Zhirong. Zhongguo duiwai guanxi xinlun: diyuan zhengzhi yu linbang waijiao yanjiu [Chinese Foreign Relations: New Perspectives on Geopolitics and the Good Neighbour Policy]. Beijing: Guji chubanshe. 2008. 434 p.

57. Wendt, Alexander. Social Theory of International Relations. Cambridge: Cambridge University Press. 1999. 429 p.

58. Zhao Tingyang. The "China Dream" in Question / "Economic and Political Studies" 2014. Vol. 2. No.1.

59. Diyuan zhanlue yu daguo anquan [Geostrategy and Security of Great Power]. Nigula Chaqiang, Shen Weilie, Pu Ning zhu. Beijing: Jiefangjun chubanshe. 2012. 374 p. 


\section{Мировая политика / World Politics}

60. Chen Li. Zhanlue dili lun [Strategical Geography]. Beijing: Jiefangjun chubanshe. 1990. 349 p.

61. Zhao Tingyang. All-Under-Heaven and Methodological Relationism. An Old Story and New World Peace, in Contemporary Chinese Political Thought: Debates and Perspectives. Edited by Fred Dallmayr and Zhao Tingyang. Kentucky: The University Press of Kentucky. 2012. 283 p.

62. Zhao Tingyang. Tianxia tixi: shijie zhidu zhexue daolun [The Tianxia System: An Introduction to the Philosophy of the World Institution]. Beijing: Zhongguo renmin chubanshe. 2011. 271 p.

63. Wang Zaibang. On Connotations and Conditions in China's New SOP / "Contemporary International Relations". 2013. Vol. 23, No. 2.

64. Su Changhe. Evolution of International Order / "Contemporary International Relations". 2014. Vol. 24 No. 4.

65. China and the International System: Becoming a World Power. Edited by Huang Xiaoming, Rober Patman. London \& New York: Routledge. 2013. 229 p.

66. Huang Jing. The Clash in Public Opinion between Europe and China: What, How and Why / «Contemporary International Relations». 2010. Vol. 20 No. 2.

67. Pan Zhongqi (ed.). Conceptual Gaps in China-EU Relations: Global Governance, Human Rights and Strategic Partnerships. Palgrave Macmillan. 2012. 267 p.

68. Wang Honggang. How Can the U.S. and China Build a "Cooperative Partnership"? / "Contemporary International Relations". 2011. Vol. 21, No. 4.

69. Yuan Peng. On the Changes in the International Order / «Contemporary International Relations». 2014. Vol. 24 No. 4.

70. Zhang Baohui. Chinese Foreign Policy in Transition: Trends and Implications / Journal of Current Chinese Affairs. 2010. Vol. 35. No. 2.

71. Xi Laiwang. Waijiao moulue: zai zhanxin de shijie geju zhong yunchou weiwo [Diplomatic Stratagems: Development of Strategic Blueprint in the Context of Newly Formated World Structure]. Beijing: Hongqi chubanshe. 1996. 462 p.

72. Wuthnow, Joel. Chinese Diplomacy and the UN Security Council: Beyond the veto. London \& New York: Routledge. 2013. (Electronic edition). $220 \mathrm{p}$.

73. Hu Shuxiang (ed.). Zhongguo waijiao yu guoji fazhan zhanlue yanjiu. [The Diplomacy of China and the Strategy of International Development]. Beijing: Zhongguo renmin daxue chubanshe. 2009. 351 p.

74. Mao Tszedun. Izbranyye proizvedeniya. Tom 4. Izdaniye literatury na inostrannykh yazykakh [Mao Zedong. Selected Works]. Pekin. 1969.

75. Fu Mengzi. China's International Influence / “Contemporary International Relations”. 2011. Vol. 21. No. 2.

76. Qin Yaqing (ed.). Guoji tixi yu Zhongguo waijiao [International System and China's Diplomacy]. Beijing: Shiji zhishi chubanshe. 2009. 401 p.

77. Chu Shulong, Jin Wei. Zhongguo waijiao zhanlue he zhengce [China's Foreign Strategy and Policy]. Beijing: Shishi chubanshe. 2008. 495 p.

78. Guoji guanxi shiyong shouce. Huan Rihan, Yao Yufei zhubian. [Practical Handbook of International Relations. Edited by Huan Rihan, Yao Yufei]. Tianjing: Tianjing renmin chubanshe. 2013. 311 p.

79. Lin Hongyu. From Passive to Active / «Contemporary International Relations». 2014. Vol. 24 No. 4.

80. Zhang Shiping. Zhongguo haiquan [Sea Power of China]. Beijing: Renmin ribao chubanshe. 2009. 347 p.

81. Wang Wei. Diyuan zhengzhi yu Zhongguo guojia anquan [Geopolitics and National Security of China]. Beijing: Junshi yiwen chubanshe. 2009.

82. Zhongguo "Zouchuqu" zhanlue shi nian huigu: chengjiu yu tiaozhan / "Xiangdai guoji guanxi" 2011 nian di 8 qi [Ten Years of China's "Go Abroad” Strategy: Results and Challenges / "Contemporary International Relations"].

83. Ye Zicheng. Luquan fazhan yu daguo xingshuai: diyuanzhengzhi huangjing yu Zhongguo heping fazhande diyuan zhanlue xuanze. [Development of Land Power and Great Power's Rise and Fall: the Environment of Geopolitics and the Choice of Geostrategy of China's Peaceful Development]. Beijing. Xinxi chubanshe. 2007. 336 p.

84. Lou Yaoliang. Diyuan zhengzhi yu Zhongguo guofang zhanlue [Geopolitics and China's Strategy of National Defence]. Tianjing: Tianjing Renmin chubanshe. 2002. 287 p.

85. Zhang Zhirong. Zhongguo duiwai guanxi xinlun: diyuan zhengzhi yu linbang waijiao yanjiu [Chinese Foreign Relations: New Perspectives on Geopolitics and the Good Neighbour Policy]. Beijing: Guji chubanshe. 2008. 434 p.

86. Wendt, Alexander. Social Theory of International Relations. Cambridge: Cambridge University Press. 1999.429 p.

87. Zhao Tingyang. The "China Dream" in Question / "Economic and Political Studies" 2014. Vol. 2. No.1.

88. Diyuan zhanlue yu daguo anquan [Geostrategy and Security of Great Power]. Nigula Chaqiang, Shen Weilie, Pu Ning zhu. Beijing: Jiefangjun chubanshe. 2012. 374 p.

89. Chen Li. Zhanlue dili lun [Strategical Geography]. Beijing: Jiefangjun chubanshe. 1990. 349 p.

90. Zhao Tingyang. All-Under-Heaven and Methodological Relationism. An Old Story and New World Peace, in Contemporary Chinese Political Thought: Debates and Perspectives. Edited by Fred Dallmayr and Zhao Tingyang. Kentucky: The University Press of Kentucky. 2012. 283 p.

91. Zhao Tingyang. Tianxia tixi: shijie zhidu zhexue daolun [The Tianxia System: An Introduction to the Philosophy of the World Institution]. Beijing: Zhongguo renmin chubanshe. 2011. $271 \mathrm{p}$.

92. Wang Zaibang. On Connotations and Conditions in China's New SOP / "Contemporary International Relations". 2013. Vol. 23, No. 2.

93. Su Changhe. Evolution of International Order / “Contemporary International Relations”. 2014. Vol. 24 No. 4. 


\section{Международные отношения / International Relations / № 3 / 2015}

94. China and the International System: Becoming a World Power. Edited by Huang Xiaoming, Rober Patman. London \& New York: Routledge. 2013. 229 p.

95. Huang Jing. The Clash in Public Opinion between Europe and China: What, How and Why / «Contemporary International Relations». 2010. Vol. 20 No. 2.

96. Pan Zhongqi (ed.). Conceptual Gaps in China-EU Relations: Global Governance, Human Rights and Strategic Partnerships. Palgrave Macmillan. 2012. 267 p.

97. Wang Honggang. How Can the U.S. and China Build a "Cooperative Partnership"? / "Contemporary International Relations". 2011. Vol. 21, No. 4.

98. Yuan Peng. On the Changes in the International Order / «Contemporary International Relations». 2014. Vol. 24 No. 4.

99. Zhang Baohui. Chinese Foreign Policy in Transition: Trends and Implications / Journal of Current Chinese Affairs. 2010. Vol. 35. No. 2.

100. Xi Laiwang. Waijiao moulue: zai zhanxin de shijie geju zhong yunchou weiwo [Diplomatic Stratagems: Development of Strategic Blueprint in the Context of Newly Formated World Structure]. Beijing: Hongqi chubanshe. 1996. 462 p.

101. Wuthnow, Joel. Chinese Diplomacy and the UN Security Council: Beyond the veto. London \& New York: Routledge. 2013. (Electronic edition). $220 \mathrm{p}$.

102. Hu Shuxiang (ed.). Zhongguo waijiao yu guoji fazhan zhanlue yanjiu. [The Diplomacy of China and the Strategy of International Development]. Beijing: Zhongguo renmin daxue chubanshe. 2009. $351 \mathrm{p}$.

103. Mao Tszedun. Izbranyye proizvedeniya. Tom 4. Izdaniye literatury na inostrannykh yazykakh [Mao Zedong. Selected Works]. Pekin. 1969.

104. Fu Mengzi. China's International Influence / “Contemporary International Relations”. 2011. Vol. 21. No. 2.

105. Qin Yaqing (ed.). Guoji tixi yu Zhongguo waijiao [International System and China's Diplomacy]. Beijing: Shiji zhishi chubanshe. 2009. $401 \mathrm{p}$.

106. Chu Shulong, Jin Wei. Zhongguo waijiao zhanlue he zhengce [China's Foreign Strategy and Policy]. Beijing: Shishi chubanshe. 2008. 495 p.

107. Guoji guanxi shiyong shouce. Huan Rihan, Yao Yufei zhubian. [Practical Handbook of International Relations. Edited by Huan Rihan, Yao Yufei]. Tianjing: Tianjing renmin chubanshe. 2013. 311 p.

108. Lin Hongyu. From Passive to Active / «Contemporary International Relations». 2014. Vol. 24 No. 4.

109. Zhang Shiping. Zhongguo haiquan [Sea Power of China]. Beijing: Renmin ribao chubanshe. 2009. 347 p.

110. Wang Wei. Diyuan zhengzhi yu Zhongguo guojia anquan [Geopolitics and National Security of China]. Beijing: Junshi yiwen chubanshe. 2009.

111. Zhongguo "Zouchuqu" zhanlue shi nian huigu: chengjiu yu tiaozhan / "Xiangdai guoji guanxi" 2011 nian di 8 qi [Ten Years of China's "Go Abroad" Strategy: Results and Challenges / "Contemporary International Relations"].

112. Ye Zicheng. Luquan fazhan yu daguo xingshuai: diyuanzhengzhi huangjing yu Zhongguo heping fazhande diyuan zhanlue xuanze. [Development of Land Power and Great Power's Rise and Fall: the Environment of Geopolitics and the Choice of Geostrategy of China's Peaceful Development]. Beijing. Xinxi chubanshe. 2007. 336 p.

113. Lou Yaoliang. Diyuan zhengzhi yu Zhongguo guofang zhanlue [Geopolitics and China's Strategy of National Defence]. Tianjing: Tianjing Renmin chubanshe. 2002. 287 p.

114. Zhang Zhirong. Zhongguo duiwai guanxi xinlun: diyuan zhengzhi yu linbang waijiao yanjiu [Chinese Foreign Relations: New Perspectives on Geopolitics and the Good Neighbour Policy]. Beijing: Guji chubanshe. 2008. 434 p.

115. Wendt, Alexander. Social Theory of International Relations. Cambridge: Cambridge University Press. 1999.429 p.

116. Zhao Tingyang. The "China Dream" in Question / "Economic and Political Studies" 2014. Vol. 2. No.1.

117. Diyuan zhanlue yu daguo anquan [Geostrategy and Security of Great Power]. Nigula Chaqiang, Shen Weilie, Pu Ning zhu. Beijing: Jiefangjun chubanshe. 2012. 374 p.

118. Chen Li. Zhanlue dili lun [Strategical Geography]. Beijing: Jiefangjun chubanshe. 1990. 349 p.

119. Zhao Tingyang. All-Under-Heaven and Methodological Relationism. An Old Story and New World Peace, in Contemporary Chinese Political Thought: Debates and Perspectives. Edited by Fred Dallmayr and Zhao Tingyang. Kentucky: The University Press of Kentucky. 2012. 283 p.

120. Zhao Tingyang. Tianxia tixi: shijie zhidu zhexue daolun [The Tianxia System: An Introduction to the Philosophy of the World Institution]. Beijing: Zhongguo renmin chubanshe. 2011. 271 p.

121. Wang Zaibang. On Connotations and Conditions in China's New SOP / “Contemporary International Relations”. 2013. Vol. 23, No. 2.

122. Su Changhe. Evolution of International Order / "Contemporary International Relations". 2014. Vol. 24 No. 4.

123. Manoylo A.B. Informacionno-psihologisheskie tehnologii razresheniya sovremennih konfliktov. // Vlast. -2008. - №5. S.27-30.

124. Budaev A.B. Prisutstvie Rossii v Brazilii: «myagkaya sila» v dvustoronnih otnosheniyah. // Latinskaya Amerika. 2013. № 5. S. 61-65. 